\title{
Cardiac CathLab-based stroke thrombectomy routine service by the BRAIN team in a recently established Thrombectomy-Capable Stroke Center in Poland
}

\author{
Krzysztof Pawłowski', Jacek Klaudel², Artur Dziadkiewicz³, Alicja Mączkowiak, Marek Szołkiewicz' \\ 'Kashubian Center for Heart and Vascular Diseases, Pomeranian Hospitals, Wejherowo, Poland \\ 2Department of Invasive Cardiology, St. Adalbert's Hospital, Copernicus PL, Gdańsk, Poland \\ ${ }^{3}$ Department of Neurology and Stroke, Pomeranian Hospitals, Wejherowo, Poland
}

Correspondence to:

Krzysztof Pawłowski, MD,

Kashubian Center for Heart and Vascular Diseases,

Pomeranian Hospitals,

Jagalskiego 10, 84-200

Wejherowo, Poland,

phone: +48 585727434

e-mail:

krzysztof.pawlowski@wp.pl

Copyright by the

Author(s), 2021

Kardiol Pol. 2021;

79 (6): 684-686:

DOI: $10.33963 /$ KP.a2021.0013

Received:

March 26, 2021

Revision accepted:

May 14, 2021

Published online:

May 18, 2021

\section{INTRODUCTION}

There is level 1a evidence for mechanical thrombectomy (MT) in the management of large-vessel occlusion (LVO), as it reduces stroke-related disability [1]. In Poland, there is a large unmet need to deliver MT to LVO stroke patients in a timely manner. Poland; a country of 38 million inhabitants where the MT service is presently limited to 20 Comprehensive Stroke Centers (MT-CSC), which equates to 0.5 centers per 1 million population [2,3]. Indeed, the shortage of MT centers and operators results in a severe under-treatment of the Polish LVO stroke patient population (MT rate in 2020 of only about $3.1 \%$ ischaemic strokes, compared to about $8.1 \%$ in neighboring Germany [4]). Furthermore, the Polish MT-CSC sparsity results in transportation-related significant MT delays and MT treatment denials [2, 3].

We provide a practical description of how to set up a cardiology cathlab-based Thrombectomy-Capable Stroke Center (TCSC) using the existing facilities and local multi-specialty collaboration centered around stroke neurology as the heart of the service [5-7]. We have coined the term the "BRAIN team" (Basic cathlab staff, Radiologist, Anesthesiologist, Interventionalist, stroke Neurologist). Here, we share our experience with regard to interdisciplinary cooperation, staff training, service organization and treatment protocols. The report includes treatment results in our initial series of unselected MT-eligible patients, with emphasis on intra-hospital times and radiologic and clinical outcomes.

\section{METHODS}

Kashubian Center for Heart and Vascular Diseases provides comprehensive cardiovascular services to the northern Pomerania region (2.3 million inhabitants). There is a strong in-house neurology department committed to top-level stroke care (European Stroke Organization highest - Diamond - Angels Quality Award status).

As the hospital does not possess a dedicated neuroradiology department, we have followed the World Federation for Interventional Stroke Treatment (WIST) structured training in stroke MT [8]. WIST emphasizes the role of simulator and team training along with the operator hands-on training, requires the results to be available for audit, promotes quality control and promotes a competence-based rather than time-based approach [8] that is consistent with Polish legal regulations $[2,3]$.

Along with other forms of MT training, the Kashubian Center stroke interventionists rotated into a level 1 stroke center (CSC) to gain practical skills and operator procedural requirements in MT. In-house standard operating procedures and checklists were developed in collaboration with the local stroke neurology team. MT-eligible consecutive patients were identified according to the international stroke and neuroradiology guidelines.

In statistical analysis, categorical variables are presented as numbers and percentages, and continuous variables are expressed as means \pm standard deviation. Due to a small sample size, only descriptive statistics have been performed. 


\section{RESULTS AND DISCUSSION}

The baseline clinical and procedural characteristics of the initial case series $(n=15)$ are provided, along with individual patient outcomes, in Supplementary material, Tables S1-S3. All target vessels were completely occluded ( $\mathrm{TICl} 0$ ) on initial angiograms, despite the background thrombolytic treatment in $86.7 \%$ of patients (Supplementary material, Table S1). To optimize the first-pass effect, we routinely adopted the SAVE (Stent-retriever Assisted Vacuum-locked Extraction) technique; the principal technique that we learned while on CSC rota. Figure 1 shows typical examples of the angiographic efficacy of the procedure.
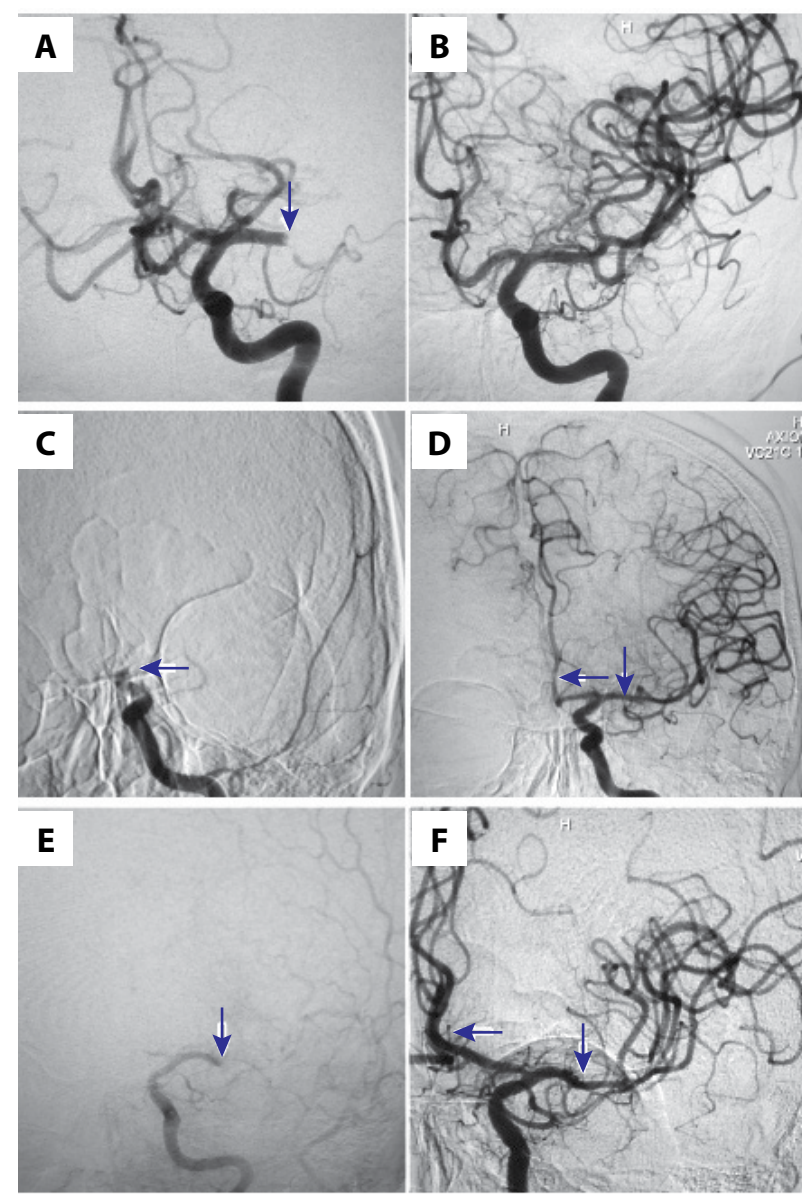

Figure 1. Typical angiographic images of brain-saving procedures performed by a multidisciplinary BRAIN team in our stroke thrombectomy center. A. Proximal occlusion of the left middle cerebral artery (L-MCA, arrow). B. Final result after mechanical thrombectomy (right, two passes) in a 67-year-old woman presenting with a large left haemispheric stroke (NIHSS 24) and contraindications to thrombolytic therapy. Discharge NIHSS was 3 (mRS 2). This was the first patient treated in our center. C. Carotid T-occlusion (left, arrow). D. Final result (arrows indicate good flow in both ACA and MCA) after mechanical thrombectomy (single-pass effect) in an 83-year old woman presenting with a large left hemispheric stroke (NIHSS 26). The patient received thrombolysis. Discharge NIHSS was 9 (mRS 3). E. Left MCA occlusion (arrow) in a 67-year-old man with NIHSS of 6 and severe aphasia. The patient received thrombolysis. A tandem lesion was identified. The L-MCA occlusion was treated first. F. Final result (arrows indicate good flow in both ACA and MCA). Carotid stenting was performed after thrombectomy (not shown). Discharge NIHSS was 2 (mRS 1)
Our mean door-to-computed tomography time was only $11( \pm 7)$ minutes, LVO diagnosis-to-groin $109( \pm 32)$ minutes, door-to-groin $133( \pm 37)$ minutes, groin-to-first-pass 49 ( \pm 26$)$ minutes, and groin-to-recanalization $93( \pm 55)$ minutes. A balloon guide-catheter was used in all but one cases. Femoral approach was our default, brachial access was used twice. $\mathrm{TICl} 2 \mathrm{~b} / 3$ was achieved in $93 \%$ of cases, $\mathrm{TICl}$ 0 rate was $0 \%$. Embolism to a new territory rate was $6.7 \%$. No intracranial hemorrhage occurred. The only serious, procedure-related complication was retroperitoneal hemato$\mathrm{ma}$, which resolved with conservative management. There were three in-hospital deaths unrelated to the procedure and no further deaths by 30 days. Functional independence ( $m R S \leq 2)$ was $30 \%$ at 30 days.

The fundamental finding from this work is that it is feasible and safe to establish a much needed regional MT service (TCSC; level 2 stroke center) in Poland within a high-volume cardiac cath-lab that is equipped to meet the requirements for intracranial procedures. Such a service should be based on local multi-specialty collaboration between expert stroke neurologists and expert interventional cardiologists with supra-aortic artery skills and MT training as per legal requirements. Even though our report includes the center's learning curve (zero MT procedures outside the present report), our MT outcomes have been well within the safety margins. In particular, $\mathrm{TICl} 2 \mathrm{~b} / 3$ was achieved in 93\% (required $>60 \%$ ), embolization to new territories was $7 \%$ (required $<15 \%$ ) and intracranial hemorrhage was $0 \%$ (required $<10 \%$ ) [9].

There is irrefutable evidence that delays in MT treatment due to long inter-hospital transport times have a significant negative effect on clinical outcomes. Unnecessary patient transportation should be avoided and if MT can be performed on-site, transporting LVO stroke patients to other centers for MT may be considered unethical [10-12].

At the beginning of this project, our multidisciplinary team set clear objectives for the formation of a TCSC and a two-year comprehensive plan that included detailed training steps and the design of standard operating procedures.

If recent international estimates [13] are applied for Poland, the introduction of a truly operational MT network, inclusive of level 2 MT centers like ours, would result in a clinically significant reduction in stroke-related disability for 1700 additional Polish citizens each year $[2,13]$.

Mechanical thrombectomy centers based in cardiology cathlabs operate effectively worldwide including North and South America and Poland's European neighbours such as Germany or Czech Republic [7, 10, 12, 14]. We could demonstrate that the concept of cardiology-cathlab-based MT centers can be adopted safely and effectively in Poland and can increase population access to level 1 evidenced stroke care, thus reducing stroke-related disability and misery to patients, relatives and the economic impact on society $[2,3,15]$. 


\section{Article information}

Conflict of interest: None declared.

Open access: This article is available in open access under Creative Common Attribution-Non-Commercial-No Derivatives 4.0 International (CC BY-NC-ND 4.0) license, allowing to download articles and share them with others as long as they credit the authors and the publisher, but without permission to change them in any way or use them commercially. For commercial use, please contact the journal office at kardiologiapolska@ptkardio.pl.

How to cite: Pawłowski K, Klaudel J, Dziadkiewicz A, et al. Cardiac CathLab-based stroke thrombectomy routine service by the BRAIN team in a recently established Thrombectomy-Capable Stroke Center in Poland. Kardiol Pol. 2021; 79(6): 684-686, doi: 10.33963/KP.a2021.0013.

\section{REFERENCES}

1. Hopkins LN, Holmes DR. Public health urgency created by the success of mechanical thrombectomy studies in stroke. Circulation. 2017; 135(13): 1188-1190, doi: 10.1161/CIRCULATIONAHA.116.025652, indexed in Pubmed: 28348088.

2. Witkowski A. Mechanical thrombectomy for ischemic stroke: why is it still a gleam in people's eyes in Poland? Kardiol Pol. 2020; 78(7-8): 802-803, doi: 10.33963/KP.15568, indexed in Pubmed: 32844617.

3. Musiałek P, Kowalczyk ST, Klecha A. Where and how to treat a man presenting up to 4 hours after cerebral large-vessel occlusion to a thrombectomy-capable major regional hospital. Kardiol Pol. 2020; 78(4): 354-356, doi: 10.33963/KP.15303, indexed in Pubmed: 32336070.

4. Richter D, Eyding J, Weber R, et al. Analysis of nationwide stroke patient care in times of COVID-19 pandemic in germany. Stroke. 2021; 52(2): 716-721, doi: 10.1161/STROKEAHA.120.033160, indexed in Pubmed: 33356382.

5. White CJ. Acute stroke intervention: the role of interventional cardiologists. J Am Coll Cardiol. 2019; 73(12): 1491-1493, doi: 10.1016/j. jacc.2018.12.071, indexed in Pubmed: 30922480.
6. Hopkins LN. Mechanical thrombectomy for ischemic stroke: a role for cardiology! Kardiol Pol. 2020; 78(7-8): 798-799, doi: 10.33963/KP.15565, indexed in Pubmed: 32844614.

7. Guidera SA, Aggarval S, Walton JD, et al. Mechanical thrombectomy for acute ischemic stroke in the cardiac catheterization laboratory. JACC Cardiovasc Interv. 2020; 13(7): 884-891, doi: 10.1016/j.jcin.2020.01.232, indexed in Pubmed: 32273100.

8. Mathias K. Mechanical thrombectomy for ischemic stroke: multispecialty team training in stroke mechanical thrombectomy to optimize thrombectomy deliverability. Kardiol Pol. 2020; 78(7-8): 799-801, doi: 10.33963/KP.15566, indexed in Pubmed: 32844615.

9. Lavine SD, Cockroft K, Hoh B, et al. Training guidelines for endovascular ischemic stroke intervention: an international multi-society consensus document. AJNR Am J Neuroradiol. 2016;37(4):E31-E34, doi: 10.3174/ajnr. A4766, indexed in Pubmed: 26892982.

10. Sievert $\mathrm{K}$, Bertog $\mathrm{S}$, Hornung $\mathrm{M}$, et al. Mechanical thrombectomy for ischemic stroke: "time is brain" is a no-brainer. Kardiol Pol. 2020; 78(7-8): 801-802, doi: 10.33963/KP.15567, indexed in Pubmed: 32844616.

11. Jahan R, Saver JL, Schwamm LH, et al. Association between time to treatment with endovascular reperfusion therapy and outcomes in patients with acute ischemic stroke treated in clinical practice. JAMA. 2019; 322(3): 252-263, doi: 10.1001/jama.2019.8286, indexed in Pubmed: 31310296.

12. Alkhouli M, Alqahtani F, Hopkins LN, et al. Clinical outcomes of on-site versus off-site endovascular stroke interventions. JACC Cardiovasc Interv. 2020; 13(18): 2159-2166, doi: 10.1016/j.jcin.2020.05.025, indexed in Pubmed: 32861630

13. McMeekin $P$, Flynn D, Allen $M$, et al. Estimating the number of UK stroke patients eligible for endovascular thrombectomy. Eur Stroke J. 2017; 2(4): 319-326, doi: 10.1177/2396987317733343, indexed in Pubmed: 29900409.

14. Alvarez CA. Mechanical thrombectomy for ischemic stroke: interventional cardiology fills the fundamental gap in the system. Kardiol Pol. 2020; 78(7-8): 804-806, doi: 10.33963/KP.15570, indexed in Pubmed: 32844619.

15. Musiałek P, Kowalczyk ST, Klecha A. Mechanical thrombectomy for ischemic stroke: Poland-time to move on! Authors' reply. Kardiol Pol. 2020; 78(7-8): 806-807, doi: 10.33963/KP.15571, indexed in Pubmed: 32844620. 